\title{
Serebral palside spastisitenin ortopedik tedavisi
}

\section{Orthopedic treatment of spasticity in cerebral palsy}

\author{
Murat Celal Sözbilen ${ }^{1}$, Emre Çullu² \\ ${ }^{1}$ Dr. Behçet Uz Çocuk Hastalıkları ve Cerrahisi Eğitim Araştırma Hastanesi, Ortopedi Kliniği, İzmir \\ ${ }^{2}$ Adnan Menderes Üniversitesi Tıp Fakültesi, Ortopedi ve Travmatoloji Anabilim Dalı, Aydın
}

\begin{abstract}
Serebral palsi, çocukluk çağının en çok karşılaşılan nörolojik özürlülük nedenlerinden biridir. Günümüzde doğum öncesi ve perinatal bakımın giderek iyileştirilmesiyle birlikte, riskli gebelikler yakın takip edilebilmektedir. Yenidoğan yoğunbakım ünitelerinin gelişmesiyle de prematür ve düşük doğum ağırlıklı bebekler yaşatılabilmektedir. Bu nedenle serebral palsi insidansı son dönemde 1000 canlı doğumda 2-2,5 seviyelerine kadar yükselmiştir. Bu durumda, bu çocuklara erken ve doğru tanının koyulabilmesi spastisite tedavisinin başarısını arttıracaktır. Spastik tip, serebral palsi alt tipleri içerisinde en çok karşılaşılandır (\%80). Spastisitede ana patolojinin santral sinir sistemi olması nedeniyle ortopedik açıdan yapılabilecekler, kas-iskelet sistemindeki spastisitenin tedavi edilmesidir. Ortopedik açıdan serebral palsili çocuğun yaşam kalitesinin ve hareketinin en iyi hale getirilmesi çalışılmalıdır. Bu amaçla, hasta özelinde çok iyi değerlendirilmeli, fizik tedavi ve çocuk nörolojisiyle birlikte multidisipliner olarak ortopedik tedavilere karar verilmelidir. Bu anlamda, erken çocukluk döneminden başlayan spastisite tedavisi (botulinum toksin A uygulamaları, fizik tedavi), ilerleyen dönemde yumuşak doku uzatma ve kemik ameliyatlarına kadar uzanabilen geniş bir tedavi araIığını kapsar. Amaç tek tek sorunların çözümü değil, olabildiğince genel olarak fonksiyonların düzeltilmesi ve kalıcı deformasyonların engellenmesi olmalıdır. Spastisite uzun süreli bir tedavi gerektirmektedir ve her aşamada fonksiyonlar adım adım iyileştirilmeye çalışılmalıdır.
\end{abstract}

Anahtar sözcükler: serebral palsi; spastisite; botulinum toksin A

erebral palsi (SP) progresif bir ensefalopati olmamasına karşın, kas-iskelet sisteminde ilerleyici yöndeki sorunların ortaya çıktığı bir hastalıktır. Anormal kuvvetler ve spastisite nedeniyle büyüyen kemiklerde ve eklemlerde ilerleyici deformasyonlar ve kontraktürler gelişebilmektedir. ${ }^{[1,2]}$ Hareket bozuklukları açısından sınıflandırıldığında spastik, diskinetik, miks, ataksik, hipotonik tipleri
Cerebral palsy is one of the most common causes of neurological disability encountered in childhood. Today, with the prenatal and perinatal care being gradually improved, risky pregnancies can be followed closely. At the same time, with the development of newborn intensive care units, premature and low birth weight infants can survive. For this reason, the incidence of cerebral palsy has increased up to levels of 2-2.5 in 1000 live births over the recent years. In this case, early and accurate diagnosis of these children will increase the success of spasticity treatment. Spastic type is the most common type encountered among cerebral palsy subtypes (80\%). As the main pathology in spasticity is the central nervous system, what can be achieved orthopedically is the treatment of spasticity in the musculoskeletal system. Orthopedically, what is attempted to achieve should be the optimization of quality of life and movement of the child with cerebral palsy. For this purpose, this disorder should be evaluated very well on patient basis, and orthopedic treatment should be determined as multidisciplinary treatment with physical therapy and pediatric neurology. In this sense, spasticity treatment starting at early childhood includes a broad range of treatments (botulinum toxin A applications, physical therapy) that can, in the future, be extended into soft tissue lengthening, and bone surgery. The goal should not be to solve problems one by one, but to fix the overall functions as general as possible, and to prevent permanent deformities. Spasticity requires a long-term treatment and functionability of the patient, and the treatment should attempt to improve the functions step by step.

Key words: cerebral palsy; spastisity; botulinum toxin A

olup tedavi hastaya özel olarak topografik sınıflama (monoplejik, hemiplejik, diplejik, triplejik) ve kaba motor fonksiyon sınıflama sistemi kullanılarak planlanır. Büyüyen çocukta ortopedik açıdan tedavi yönetimiyle en etkili olunan alt tip spastisite olup cerrahi ve konservatif metodlarla kalıcı kas-iskelet patolojilerinin oluşması ya da ilerlemesinin önüne geçilmesine çalışılır. ${ }^{[3-5]}$

- Illetişim adresi: Prof. Dr. Emre Çullu, Adnan Menderes Üniversitesi Tıp Fakültesi, Ortopedi ve Travmatoloji Anabilim Dalı, Aydın Tel: 0532 - 4560046 e-posta: ecullu@superonline.com

- Geliș tarihi: 1 Ekim $2018 \quad$ Kabul tarihi: 1 Ekim 2018 
Spastisiteye bağlı gelişen kas iskelet sistemi sorunları;

- Eklem kontraktürleri (ROM-hareket kısıtlılığı),

- Kas-tendon kısalıkları,

- Yürüyüş bozukluğu (makaslama, ekin yürüyüş),

- Omurga patolojileri (skolyoz),

- Eklem çıkıkları ve

- Kemik deformasyonlarıdır.

\section{SPASTISITEDE ORTOPEDIK TEDAVIDE AMAÇ VE ZAMANLAMA}

Kaba motor fonksiyon sınıflaması (GMFCS) serebral palsili hastanın tedavi planlamasında uygun tedavi yönteminin seçilmesinde yol gösterir. SP'li çocuklardaki beklenti düzeyinin objektif kriterler içerisinde belirlenmesinde (motor fonksiyon tahmini) ve bu hedefe uygun ortopedik yaklaşımın tercih edilmesinde en önemli yol göstericidir. İki-12 yaş arası SP'li çocuklarda motor fonksiyon tahmininde, GMFCS güvenilir ve geçerli bir yöntemdir. ${ }^{[6,7]}$

Çocuğun kendi ihtiyaçlarını karşılayabilmesi ve yürüyebilmesi öncelikli amaçtır. Bir yaşından sonra ilkel reflekslerden iki ya da fazlasının olması, beş yaşında oturamaması ya da sekiz yaşına kadar yürüyememiş çocukta yürüme olasılığı düşüktür.

Spastisitede 0-3 yaş arasında fizik tedavi ön plandadır. Bu dönemde kalça çevresi adduktor ve fleksör spastisitesi olan çocuklarda kalça çıkıklarına dikkat edilmelidir. Riskli hastalar yakın takip edilmelidir. Genel olarak 4-6 yaşından itibaren ortopedik cerrahi tedaviler başlar. Bu yaşlarda da fizik tedavi ön plandadır ama tıpkı kalça çıkığı riski olan $0-3$ yaş grup gibi gerekli durumlarda cerrahi öne çekilebilir. ${ }^{[5,8]}$ Her çocuk kişisel olarak değerlendirilmeli ve GMFCS yardımıyla motor fonksiyon hedefi sonuna kadar zorlanmalıdır.

Cerrahi planlama ve sıralamasında günümüzde tek veya iki seferde çok seviyeli cerrahi ön planda tercih edilmektedir. Bu şekilde, çocuğun her yılını alçılı ve ameliyatlı geçirmesinin önüne geçilir. Bu aşamaya kadar fizik tedavi ve botulinum toksin uygulamaları ile büyümenin hızlı evrelerinde spastisite, cerrahi olmayan tedaviyle engellenmeye çalışılır. Büyümenin hızlı evreleri geçildikten sonra yumuşak doku girişimleri ve kemik cerrahileri tek seferde uygulanarak çocuğun hastane yatışları, alçılı ve fizik tedavisiz geçen süresi olabildiğince aza indirilmeye çalışılır. Bu nedenle SMILE (Sequential Multilevel Interventions in the Lower Extremities) denilen, alt ekstremitenin ardışık, çok seviyeli girişimlerle tedavisi önerilmiştir. ${ }^{[9,10]}$

GMFCS 4-5 kuadriplejik hastalarda ortopedik cerrahi hasta bakımı (hijyeni), bacaklarını açabilmesi ve kolay giydirilebilmesi amaciyla uygulanır.
Cerrahi zamanlama hastaya göre tercih edilir ancak dikkat edilecek genel hususlar mevcuttur. Erken yapılan cerrahide spastisite geri dönebileceği gibi geç yapılan cerrahide de yararsız olabilir. Fizik tedavi ve botulinum toksini uygulamaları yumuşak doku işlemlerini ileri yaşlara erteleme olanağını bize sağlamaktadır. İstisna olarak kalça çevresi kasların dengesizliğine bağlı gelişen kalça çıkığında erken cerrahi gerekebilir. Serebral palsili çocuklar doğduklarında normal kalça yapısına sahiptirler ancak spastisitenin artışına bağlı kontrakte adduktorlar ve fleksörler, zayıf ekstansör ve abduktorlara baskın gelir ve kalça yarı-çıkı̆̆ına ya da çıkığına neden olur. Bu durumda cerrahi erken dönemde ön planda düşünülmelidir.

Kemik düzeltme osteotomileri genel olarak yedi yaşından sonra yapılmakta ve daha başarılı olmaktadır. ${ }^{[1,5]}$

\section{SPASTISITENIN CERRAHI DIŞI TEDAVILERi}

\section{Fizik Tedavi}

Spastisite tedavisi motor işlevi en üst düzeye çıkarmayı, kontraktür gelişimini önlemeyi amaçlar. Bunun için var olan nöromotor kapasitenin arttırılması, eklem hareket açıklıklarını arttırılması için kas germe ve güçlendirme egzersizleri yapılır. Spastisite yedi yaşına kadar fizik tedavi, ortez, botulinum toksin uygulaması ve ağızdan oral ilaç tedavisi ile azaltılabilir. ${ }^{[1,5,11,12]}$

\section{Botulinum Toksin Uygulamaları}

Clostridium botulinumdan üretilen bir nörotoksin olan botulinium toksin A sinir-kas kavşağında asetil kolin salınımını inhibe ederek iletimi engeller. Botulinum toksin $A$ uygulaması günümüzde erken dönemden itibaren spastisitenin azaltılmasında ve motor fonksiyonun iyileştirilmesinde önemli bir yer tutmaktadır.

\section{Botulinum toksin kullanım amaçları}

Kaslarda paraliziye neden olarak spastisite ve distoniyi azaltır. Bu şekilde makaslama, ekinus gibi yürüyüş bozukluklarında ve harekette düzelme elde edilebilir. Kas işlev ve eklem hareket genişliği artar. Yürüyüşün düzeltilmesi dışında fizyoterapinin kolaylaştırılmasını sağlar. Ortez kullanımı ve uyumunu arttırır. Postürün düzeltilmesiyle kişisel bakım (giyinebilme, oturabilme) ve hijyen iyileştirilir (perine temizliği). Spastisiteye bağlı ağrılı kas spazmlarını azaltarak yürüme ve hayat kalitesini arttırır.

\section{Botulinum toksinin yararsız olduğu durumlar}

Sadece dinamik spastisitede kullanılmalıdır. Kontraktürlerde etkili değildir. Tekrarlayan dozlar sonrası direnç geliş̧ebilir.

\section{Spesifik endikasyonlar}

- Spastik ekinus: En etkili olduğu spastisitelerden biridir. Altı yaş altında, dinamik ekinusu olan 
çocuklarda etkilidir. Yürüyüşü düzeltirken (ağrıyı azaltarak, yürüme mesafesini arttırarak) ayaktaki malformasyonları da azaltır. Ayak-ayak bileği (AFO) ortezlerine uyumu arttırır. Pasif germede ayak nötral pozisyona gelmiyorsa endikasyonu tartışmalıdır. ${ }^{[13-15]}$

- Adduktor spastisite: Ağrının azaltılmasında ve hasta hijyeni ve kolay bakımı için yararlıdır. Adduktorlarla birlikte grasilis ve mediyal hamstring kaslarına uygulama kalçanın çıkmasını önleyebilir ve kalça gelişimini olumlu etkiler. Tedavi için yaş sınırı yoktur. Hastaların transferi, giydirilmesi ve oturmalarında kolaylık sağlar. Reimer migrasyon indeksi >\%40-50 ise endikasyonu tartışmalıdır. ${ }^{[16]}$ Bu durumda kalçanın çıkığa gidişini engelleyemez.

- Tek seferde çok seviyeli tedavi: Spastik hareket bozukluklarında genel anestezi ya da sedoanaljezi altında tek seansta çok seviyeli uygulamanın yürüyüş analizlerinde ve çalışmalarda terapötik etkisinin daha etkili olduğu gösterilmiştir. Birçok merkez genel anestezi ihtiyacı nedeniyle (özellikle ilopsoas kası için) bu yöntemi uygulayamamaktadır. ${ }^{[17]}$

- Spastisitede ağrı: Ağrı musküler hiperaktiviteye bağlı geliştiğinde botulinum toksin A uygulaması etkili bir tedavi yöntemi olmaktadır. Bunun yanı sıra ameliyat sonrası gelişen ağrıyı ve analjezi gerekliliğini de azaltabilmektedir. ${ }^{18]}$

\section{Botulinum toksin A ne kadar süre uygulanabilir?}

Erişkinlerde uzun dönem tedavi servikal distonide sık kullanılır. Serebral palside kullanımı konusunda yapılan ileriye dönük çalışmalarda uzun dönem kullanımda GMFCS'de belirgin fonksiyonel iyileşme olduğu gözlenmiştir. ${ }^{[19]}$ Sabit kontraktür nedeniyle cerrahi gereksinimine kadar uygulanmaya devam edilebilir. Genel görüş olarak 2/3 hasta tedaviye olumlu yanıt verirken, kalanının ilk uygulamalardan sonra yarar göremeyebileceği görülmüştür. ${ }^{[20]}$ Bölüm yazarına göre iki dönem enjeksiyon sonrası botulinum toksin A tedavisinin devamı açısından hastalar tekrar değerlendirilmelidir.

\section{Yan etkiler}

a. Lokal ve sistemik yan etkileri: Vücut genelinde yorgunluk hissi, çift görme, parainfluenza benzeri semptomlar, lokal ağrı ve fonksiyonel bozulmayla giden lokal zayıflık görülebilir. Doz ayarlaması ve uygulama aralıkları dikkatli kontrol edildiği takdirde güvenlidir. Beklenmeyen etkiler genellikle hafif ve geri dönüşümlüdür. ${ }^{[21]}$

b. Sistemik botulinizm: Hayvan deneylerinden elde edilen verilere göre parenteral uygulamada $70 \mathrm{~kg}$ bir insan için toksik doz yaklaşık 3000 ünite olarak bildirilmiştir (İntramusküler $\mathrm{LD}_{50} 39 \mathrm{U} / \mathrm{kg}$, intravenöz $\left.\mathrm{LD}_{50} 40 \mathrm{U} / \mathrm{kg}\right) \cdot{ }^{[22]}$

c. Yanlış enjeksiyonun riskleri nelerdir?: Kolinerjik sinir uçlarına direkt etki gösterebilir. Retrograd aksonal transport mümkün olsa da ilk motor nöron etkilenmez. ${ }^{[23]}$

d. Enjeksiyon sırasında ağrı: Tekrarlayan çoklu enjeksiyon siklusları sonrasında özellikle uygulama sırasında ağrı olur. Sedoanaljezi çoğunlukla ağrı için yeterlidir. ${ }^{[24]}$

e. Alerji: Enjeksiyon sonrası nadiren eritem görülebilir.

\section{Anestezi}

İ̆nenin giriş bölgesinde cilt ve fasya ağrısının yanı sıra asıl ağrı, kas dokusuna verilen çözünmüş sıvı nedeniyle olur. Bu özellikle küçük çocuklarda travmatik olabilmektedir. Sedoanaljezinin amnestik etkisiyle tekrarlayan enjeksiyonlarda çocuğun uyumu ve toleransı artar. Ağrının ekarte edilmesi, palpasyonunun yanısıra botulinum toksin A'nın hedef kasa daha doğru uygulanmasını sağlar. Sedoanaljezisiz uygulamada çocuk ağrılı enjeksiyonlara direnecek ve doğru uygulama yapılamayacaktır.

Kliniğin ve tesisin teknik yeterliliğine göre analjezi, genel anestezi ve sedoanaljezi tercihi de şartlara göre seçilmektedir.

Topikal anesteziklerin ağrıı azaltmadaki etkinlikleri çok sınırı ve yetersizdir. Günümüzde tercih edilmemektedirler.

\section{Enjeksiyon dozları}

Botulinum toksin dozları ünite $(U)$ olarak hesaplanır. Piyasada yer alan botulinum toksin A tipine göre doz ayarlanmalıdır. Genel olarak kasların boyutu ve kiloya göre dozlar ünite olarak ayarlanmalı ancak tercih edilen markanın hazırlama prosedürlerine göre uygulanmalıdır. Tablo 1'de, iki yaşın üzerinde, ağırlığı 10-30 kg arasında değişen bir çocukta onabotulinum A uygulama doz aralığı verilmiştir.

\section{Dozların üst limitleri}

Çocukların tedavisinde aşağıdaki doz aralıkları genellikle güvenli kabul edilir.

- Maksimum total doz (hasta başı ve seans için): 12 $U / k g$ ve toplamda $400 U$ geçilmez.

- Büyük kaslar için üst dozlar: $6 \mathrm{U} / \mathrm{kg}$ ve toplamda $100 \cup$ geçilmez.

- Küçük kaslar için üst dozlar: $2 U / k g$ ve toplamda $50 \cup$ geçilmez.

- Enjeksiyon bölgesi başına üst doz limiti: $50 \mathrm{U}$ geçilmez. 
Tablo 1. İki yaşın üzerinde, ağırlığı 10-30 kg arasında değişen bir çocukta vücut ağırlığına göre her bir kas için ortalama $(\mathrm{U} / \mathrm{kg})$ ve total uygulanabilecek onabotulinum $\mathrm{A}$ doz tablosu

\begin{tabular}{lll}
\hline Hedef kaslar & Her kas için doz (U/kg vücut ağırlığı) & Her bir kas için toplam maksimum doz (U) \\
\hline Küçük kaslar & & $10-50$ \\
- Adduktor pollicis brevis & $1-2$ & \\
- Fleksör dijitorum superfisialis & & \\
- Fleksör dijitorum profundus & \\
- Fleksör karpi radialis & \\
- Fleksör karpi ulnaris & \\
- Fleksör pollicis longus & \\
- Pronator teres & \\
- Brachioradialis & \\
Büyük kaslar & $30-100$ \\
- Gastroknemius & \\
- Soleus & \\
- Tibialis posterior & \\
- Adduktor kaslar & \\
- Grasilis & \\
- Hamstringler &
\end{tabular}

\section{Enjeksiyon aralıkları}

Oniki haftadan erken yeni enjeksiyondan kaçınmak gerekir. Sık tekrarlayan enjeksiyonlar antikor gelişimini ve ilaca ikincil gelişen direnç sayısını arttırabilir.

\section{Enjeksiyon tekniği}

a. Gerekli materyaller

- Hipodermik iğne (27G veya 30G). Alt ekstremiteye uygulamada $4 \mathrm{~cm}$, üst ekstremiteye uygulamada $2 \mathrm{~cm}$ iğne uzunluğu olmalıdır.

- Enjektör ( $1 \mathrm{~mL}, 2 \mathrm{~mL}$ ve $5 \mathrm{~mL}$ )

- Steril \%0,9 NaCl solüsyonu

- Dermal dezenfeksiyon materyali

- Soğuk zincire uygun trasportu sağlanmış botulinum toksin A

\section{b. Enjekssiyon solüsyonunun hazırlanması}

- Flakon kutusundan çıkarılarak steril şekilde kapak açılır.

- Daha önceden steril olarak $5 \mathrm{~mL} \% 0,9 \mathrm{NaCl}$ solüsyonu çekilmiş enjektör flakona batırılır.

- Vakumlu olarak kurutulmuş içeriği bulunan flakona enjektör batırıldığında enjektör içerisindeki sıvı kendiliğinden flakona dolacaktır. Bu flakonun güvenli vakumlandığını göstermektedir.
Serum fizyolojik köpürtülmeden yavaşça şişeye doldurulmalıdır.

- Ardından flakon avuç içerisinde nazikçe yuvarlanarak ve çevrilerek çözünme sağlanır. Flakon proteinlerin denatüre edebileceği için asla çalkalanmamalıdır.

- Çözünmüş solüsyon $1 \mathrm{~mL}$ enjektörlere paylaştırılır ve 27G iğne takılır. Böylece her bölge için kullanıma hazır şırıngalar el altında olur. Hızlı uygulamanın hasta açısından morbiditeyi azaltacağı unutulmamalıdır.

- İğnenin enjektöre sıkı takıldığından emin olunmalıdır. Dar uçlu bir iğne olduğu için uygulama sırasındaki geri basınç enjektör ucunun aniden ayrılıp ilacın dışarı fışkırmasına neden olabilir.

\section{Uygulama}

Kas içerisine 2-5 lokalizasyonda uygulanır. Kılavuzluk sağlaması açısından, ultrasonografi eşliğinde, elektriksel uyarı veren yöntemlerle veya palpasyonla yapılabilir. Her uygulama esnasında enjektör pistonu geriye çekilerek vasküler yapılardan uzak olunduğu teyit edilmelidir. Tek taraflı ekstremite uygulamalarında işlem öncesi taraf işaretlemesi yapılması yaşanabilecek karışıklıkların önüne geçer. Palpasyon yönteminde iğnenin kas içerisinde olduğu, ilgili kas hareket ettirilirken iğne hareketini gözlemleyerek teyit edilmelidir. 
- Gastroknemius: Supin pozisyonunda muayene ile mediyal ve lateral gastroknemiusun başları üst $1 / 3$ kruriste palpe edilerek bulunur. Ardından distale doğru kasların en geniş olduğu bölgeye uygulanır. Mediyal için 1-2 cm, lateral için $0,5-1,5 \mathrm{~cm}$ derinlikte iğne derinliği gerekir (Şekil 1).

- Soleus: Gastroknemiusun derininde altında olduğu için soleusun palpasyonu mümkün değildir. Enjeksiyon için en uygun bölge bacağın ortasında gastroknemiusun en ince olduğu bölgedir.

- Tibialis posterior: Tibianın hemen arkasında olduğu için palpe edilemez. Mediyalden tibiaya yakın bir şekilde posterior kenarına paralel olarak iğne batırılır. Yaklaşık 2-4 cm derinlikte batırılır (Şekil 2). Ayak varus, valgusa zorlanarak iğnenin hareketliliğine bakılır.

- Mediyal hamstringler: Mediyal hamstring kaslarını popliteal fossadan proksimale doğru palpe edilir. Kas gövdesinin uyluğun posteriorunda gözlenir. Enjeksiyon 1-3 cm derinliğe yapılır (Şekil 3).

- Adduktor longus ve gracilis: Adduktor longus diz ve kalça fleksiyonda iken adduktor magnusun üzerinde palpe edilebilir. Kalça abduksiyonu ve diz ekstansiyonu ile adduktor longusun dorsomediyalinde grasilis palpe edilebilir (Şekil 4).

- illiopsoas: Anatomik derinliği ve yapısı nedeniyle uygulaması güçtür. Genel anesteziyle tüm karın duvarı kaslarının gevşemesi gerekmektedir. Umbilikus ve anterior superior iliak kanat arasındaki hattın orta bölgesi enjeksiyon alanıdır. Elle lateralden derin palpasyon yapılarak intestinal yapılar ve damar sinir yapıları orta hatta doğru itilir. Parmak uçları ile iliopsoas kas gövdesi palpe edilir. Enjeksiyon derinliği yaklaşık 2-3 cm'dir.

- Biceps brachii: Dirsek fleksiyon spastisitesinde uygulanır. Dirsek hareketleriyle kas gövdesinde olduğu teyit edilip vasküler yapılara dikkat edilmelidir.

- El bileği ve el fleksörleri: El ve el bileği fleksör spastisitesinde uygulanır. Tablo 1'de yer alan dozlara dikkat edilir. Nörovasküler yapılara yakınlık nedeniyle dikkat edilmelidir.

- Pronator teres: Önkol supinasyonunu iyileştirmek için pronator teres çoğunlukla tercih edilen kastır (Şekil 5).

- Başparmak kasları: Fleksör pollisis brevis, opponens pollisis, adduktor pollisis ve fleksör pollisis longus başparmak spastisitesinde enjeksiyon uygulanabilecek kaslardır.
Diğer Tedaviler ile

Botulinum Toksin A Tedavisinin Kombinasyonu

\section{Fizik tedavi}

Botulinum toksin uygulaması sonrası erken fizyoterapiye başlamanın olumlu etkiyi arttırdığı görülmektedir. Enjeksiyon uygulanmış kaslara pasif germe egzersizleri yapılırken antagonist kasların aktive olması sağlanır. Fizik tedavideki diğer hedefler ise fonksiyonel yeteneğin bir üst seviyeye çıkarılması ve adaptasyonudur. Fonksiyonel öğrenmenin günlük rutinde de devamı ve geliştirilmesi sağlanmalıdır (yürümenin kazanılması sonrası günlük yürüme pratiğinin devamı gibi). ${ }^{[25,26]}$

\section{Botulinum toksin A + terapötik alçılama}

Her iki tedavi yönteminin de ayak bileği hareketinde iyileşme sağladığı yürüme analizi çalışmalarında gösterilmiştir. Botulinum toksinin A uygulamasının etkisi bu şekilde daha uzar. Her iki yöntemin ayrı ayrı etkisi olsa da alçılama hasta tarafından daha zor tolere edilebilen bir yöntemdir. ${ }^{[27,28]}$ Birçok görüşe göre birlikte uygulamanın sinerjist etkiyi arttırabileceği düşünüldüğünden, enjeksiyon sonrası 1-2 haftalık alçılama yapılması önerilir. Bu durum spastik ekinus gibi dinamik ve yapısal değişiklikleri içeren karma klinik tablolarda etkili olabileceğini düşündürmektedir. ${ }^{[29-31]} \mathrm{Bu}$ konuyla ilgili tartışmalar devam etmektedir. Kay ve ark. ile Desloovere ve ark. yaptıkları çalışmalarda, alçılamanın çok az yararı olduğunu ya da hiç yararı olmadığını bildirmişlerdir. ${ }^{[32,33]}$ Mevcut çalışmalar alçılamanın yararlı etkisini göstermekte yeteri kadar veriye sahip değildir. ${ }^{[34]}$

\section{Botulinum toksin A + ortez kullanımı}

Ortez kullanımı uygulama sonrası ilk haftalarda ayak bileği eklemine destek olmaktadır. Dinamik ortezler topuk temasının sağlanmasında gereklidir, ancak etkili plantar fleksiyon yapmayı önleyebilir. Ortezler botulinum toksin A uygulamasının etkisini uzatabilir. ${ }^{[34-36]}$

\section{ilaç Tedavisi (Oral Baklofen)}

GABA-B reseptör antagonistidir. Kaslarda gevşeme ve sedasyona neden olur. Distonik hastalarda daha yararlıdır.

\section{Intratekal Baklofen Tedavisi}

Oral baklofen tedavisinin kan-beyin bariyerinden geçişi zor olması ve doza bağlı yan etkileri arttığı için için direkt beyin omurilik sıvısına (BOS) verilir. Yaygın spastisite nedeniyle yürüyemeyen, dik duramayan hastalarda sıklıkla uygulanır. İntratekal yolla belirli aralıklarla infüzyon pompası ile spinal subaraknoid aralığa ilacın verilmesidir. Yürüyemeyen, yaygın ve şiddetli (Ashworth 3 ve fazlası) spastisitesi bulunan, giydirilmesi, oturtulması zor hastalarda endikedir. BOS kaçağı, enfeksiyon, mekanik sorunlar gibi komplikasyonlar bildirilmiştir. ${ }^{[37]}$ 

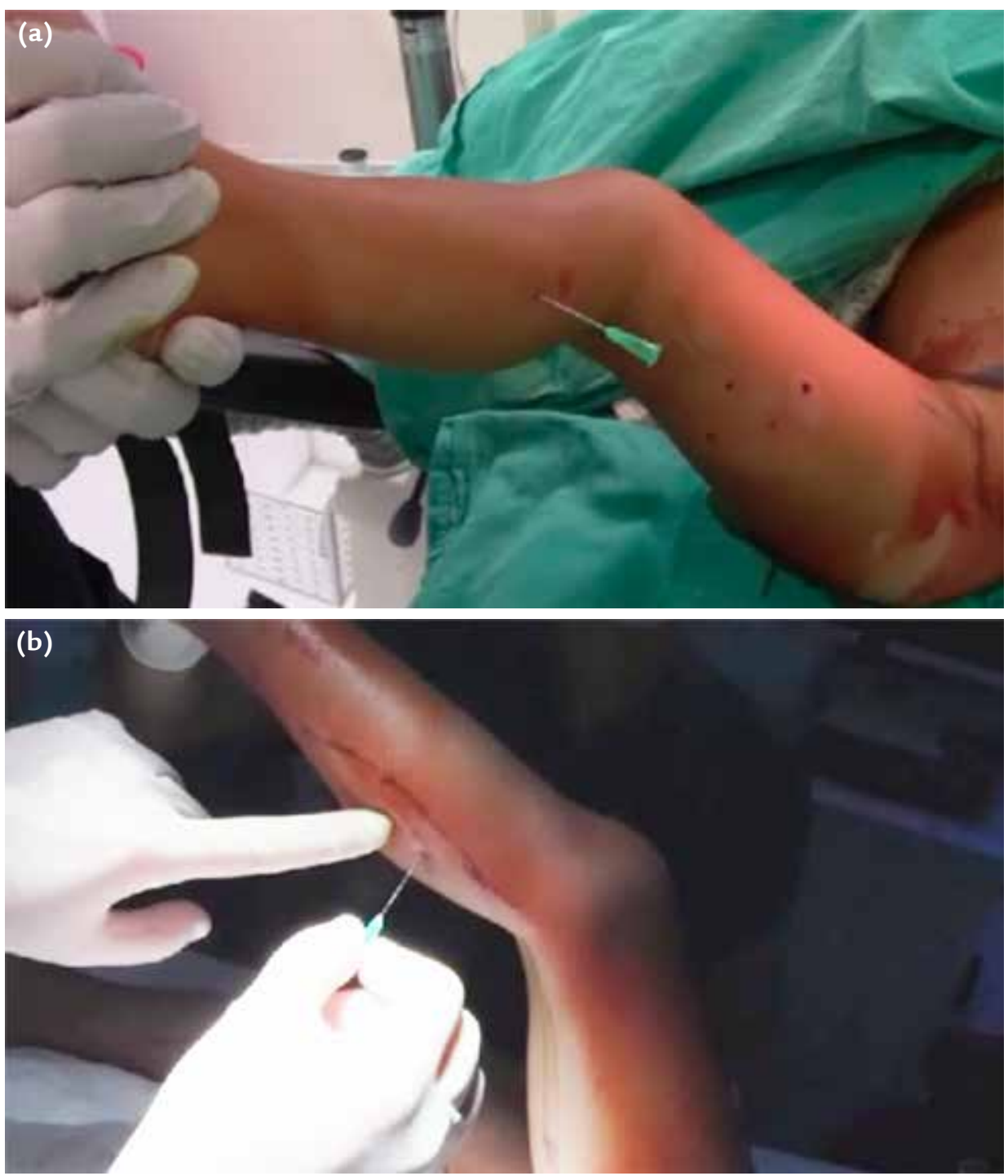

Şekil 1. a, b. Mediyal (a) ve lateral (b) gastroknemius kaslarına botulinum toksin A uygulanması.

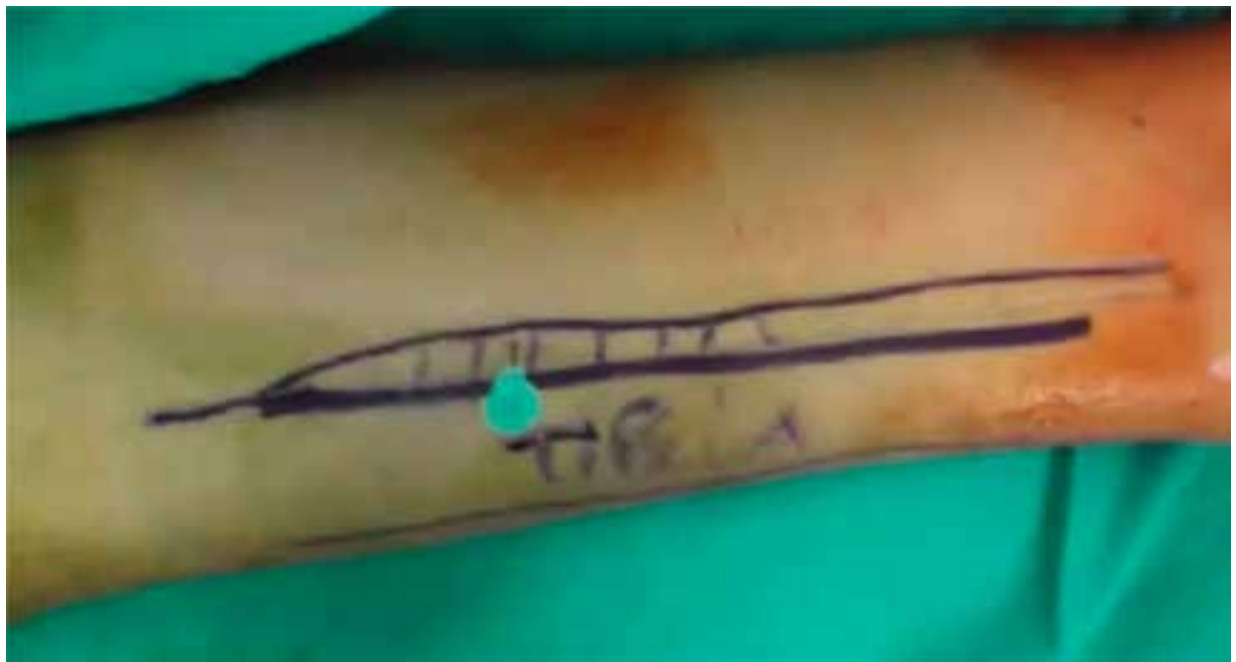

Şekil 2. Tibialis posterior botulinum toksin A uygulaması. 

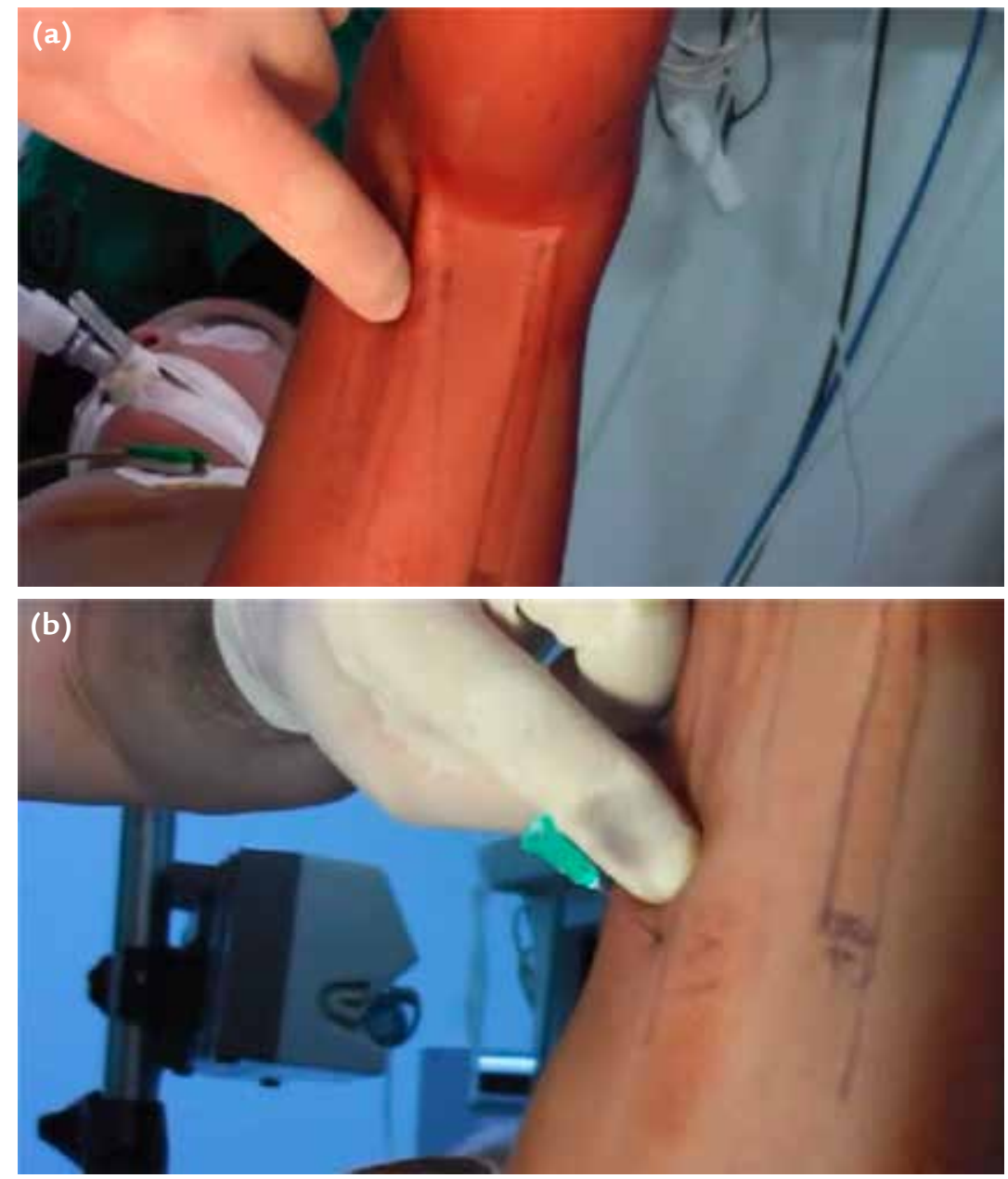

Şekil 3. a, b. Mediyal hamstring gösterilmesi (a) ve uygulaması (b).
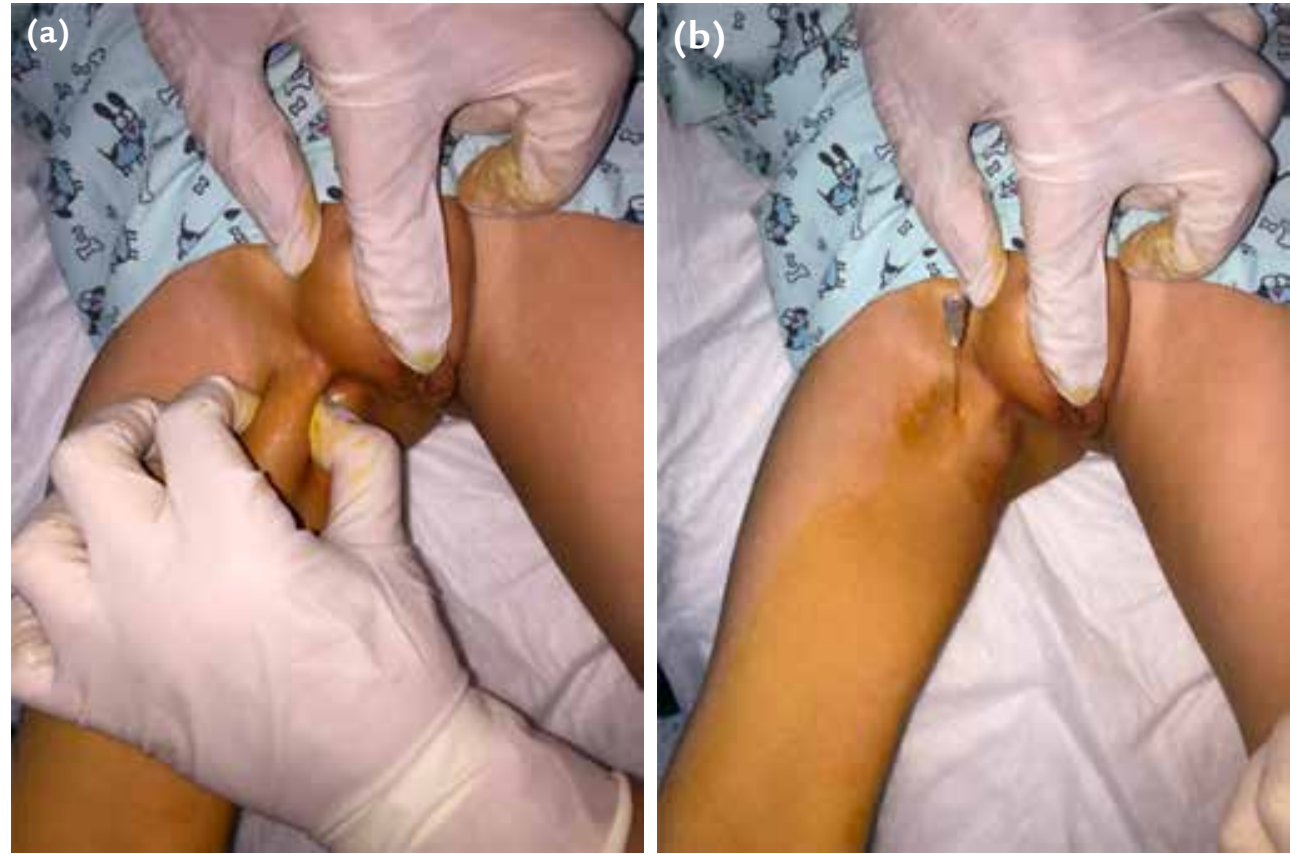

Şekil 4. a, b. Adduktor longus gösterilmesi (a) ve uygulaması (b). 

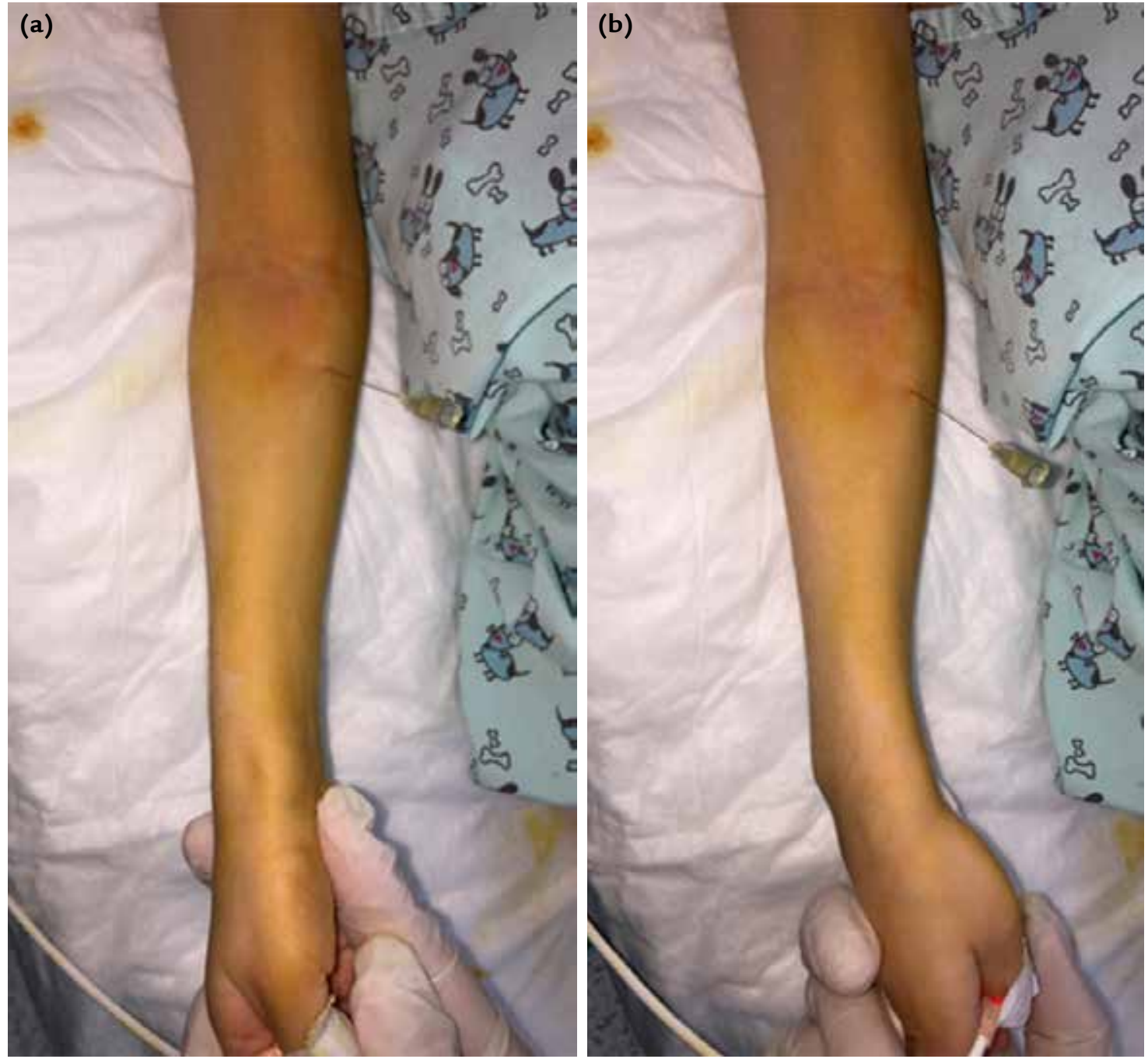

Şekil 5. a, b. Pronator teres uygulaması (a) ve pronasyon hareketi ile uygulamanın doğrulanması (b).

\section{Selektif Dorsal Rizotomi}

Spastisitede kalıcı düzelme sağlar ve daha çok alt ekstremite spastisitesini azaltmak amaciyla uygulanır. Kas liflerinden gelen duyusal geri dönüş azaltılarak spastisite azaltılır. Belirli bir bölgede dorsal kökler eksize edilir. EMG ile uyarı verilerek 2 . lomber ve 2 . sakral seviyelerin arasındaki sinir kökleri saptanır ve dorsal köklerin \%25-50'si kesilir. Yürüme potansiyeli olan, fizik tedaviye uyumlu kapasitede, alt ekstremite spastisitesi olup diğer yöntemlerden yarar görmeyen 3-8 yaş arası çocuklarda uygundur. Ameliyat sonrası çok uzun süre fizik tedaviye gereksinim doğurur. Duyu kaybı, mesane disfonksiyonu, kalça çıkığı, skolyoz, spondilolistezis gibi komplikasyonlar bildirilmiştir. ${ }^{[38]}$

\section{Ortopedik Cerrahi Tedavi}

Ortopedik cerrahi tedavi serebral palsili çocuğun oturmasını, ayakta durmasını ve yürümesini sağlayabilmek amacıyla uygulanır. Bu hedeflere ulaşmak amacıyla, kas dengesini sağlamak, eklem hareket açıklığını arttırmak, kontraktürleri gevşetmek ve ekstremite dizilimini düzeltmeye yönelik cerrahi girişimler uygulanır. Ameliyat öncesi planlama ve zamanlama önemlidir; multidisipliner olarak değerlendirilip karar verilmelidir. Her hastaya özel tedavi seçimi ve bir iki seansta çok seviyeli cerrahi girişim uygulaması yapılmalıdır. ${ }^{[2,9]}$

Tendon-kas uzatma ameliyatları ile eklem hareket açıkığının arttırılması ana ilkedir. Tendon transferlerinde ise amaç çalışan kas grubunun yönünü değiştirerek kas dengesini sağlamaya çalışmaktır. 


\section{SONUÇ}

Serebral palsili çocukta spastisite tedavisinde asıl önemli olan cerrahinin veya cerrahi dışı tedavilerin nasıl uygulandığından çok; hastaya özel değerlendirmelerin sonucunda verilen multidisipliner kararların, doğru zamanlama ile uygulanması sonucu var olan fonksiyonların üstüne yenilerini koyma hedefine ulaşmaktır. Planlı ve disiplinli uygulanmış cerrahi dışı tedaviler (botulinum toksin A, fizik tedavi, ortezleme) kaba motor fonksiyon sınıflamasında belirgin fonksiyonel iyileşmeyi sağlamakta, bu şekilde cerrahiyi erteletmekte veya kolaylaştırmaktadır.

\section{KAYNAKLAR}

1. Miller F. Cerebral Palsy. New York: Springer; 2005.

2. Yıldız C, Kılınçoğlu V, Yurttaş Y, Başbozkurt M. Serebral Paralizide Ortopedik Tedavi Prensipleri: Genel Bakış. TOTBiD Derg 2009;8:1-2.

3. HerringJA. Cerebral Palsy. Tachdjian's Pediatric Orthopaedics. Philadelphia PA: W. B. Saunders Company; 2002.

4. Morrisy R. Cerebral Palsy. Lovell and Winter's Pediatric Orthopaedics. Philadelphia: Lippincott; 2007.

5. Cullu E, editör. Çocuk Ortopedisi, 1. baskı. İstanbul: Bayçınar; 2012.

6. Palisano R, Rosenbaum P, Walter $S$, Russell D, Wood E, Galuppi B. Development and reliability of a system to classify gross motor function in children with cerebral palsy. Dev Med Child Neurol 1997;39(4):214-23.

7. Palisano RJ, Rosenbaum $\mathrm{P}$, Bartlett $\mathrm{D}$, Livingston $\mathrm{MH}$. Content validity of the expanded and revised Gross Motor Function Classification System. Dev Med Child Neurol 2008;50(10):744-50. Crossref

8. Presedo A, Oh CW, Dabney KW, Miller F. Soft-tissue releases to treat spastic hip subluxation in children with cerebral palsy. J Bone Joint Surg Am 2005;87(4):832-41. Crossref

9. Mahmudov V, Gunay H, Kucuk L, Coskunol E, Atamaz FC. Comparison of single event vs multiple event soft tissue surgeries in the lower extremities with cerebral palsy. J Orthop 2015;12:S171-5. Crossref

10. Sussman MD, Aiona MD. Treatment of spastic diplegia in patients with cerebral palsy. J Pediatr Orthop B 2004;13(2);S1-12. Crossref

11. Aiona MD, Sussman MD. Treatment of spastic diplegia in patients with cerebral palsy: Part II. J Pediatr Orthop B 2004;13(3):S13-38. Crossref

12. Aarts PB, Jongerius PH, Geerdink YA, van Limbeek J, Geurts AC. Effectiveness of modified constraint-induced movement therapy in children with unilateral spastic cerebral palsy: a randomized controlled trial. Neurorehabil Neural Repair 2010;24(6):509-18. Crossref

13. Eames NW, Baker R, Hill N, Graham K, Taylor T, Cosgrove A. The effect of botulinum toxin $A$ on gastrocnemius length: magnitude and duration of response. Dev Med Child Neurol 1999;41(4):226-32. Crossref

14. Huntley JS Bradley LJ. The Evidence Base for Botulinum Toxin Injection for the Treatment of Cerebral Palsy -Related Spasticity in the Lower Limb: The Long-Term Effects. In: Alshryda S, Huntley JS, Banaszkiewicz PA, editors. Paediatric Orthopaedics. Springer; 2017. p.369-73. Crossref
15. Sutherland DH, Kaufman KR, Wyatt MP, Chambers HG, Mubarak SJ. Double-blind study of botulinum A toxin injections into the gastrocnemius muscle in patients with cerebral palsy. Gait Posture 1999;10(1):1-9. Crossref

16. Mall V, Heinen F, Siebel A, Bertram C, Hafkemeyer U, Wissel J, Berweck S, Haverkamp F, Nass G, Döderlein L, BreitbachFaller N, Schulte-Mattler W, Korinthenberg R. Treatment of adductor spasticity with BTX-A in children with CP. a randomized, double-blind, placebo-controlled study. Dev Med Child Neurol 2006;48(1):10-3. Crossref

17. Scholtes VA, Dallmeijer AJ, Knol DL, Speth LA, Maathuis CG, Jongerius $\mathrm{PH}$, Becher JG. Effect of multilevel botulinum toxin a and comprehensive rehabilitation on gait in cerebral palsy. Pediatr Neurol 2007;36(1):30-9. Crossref

18. Wissel J, Müller J, Dressnandt J, Heinen F, Naumann M, Topka $H$, Poewe $W$. Management of spasticity associated pain with botulinum toxin A. J Pain Symptom Manage 2000;20(1):449. Crossref

19. Koman LA, Brashear A, Rosenfeld S, Chambers H, Russman B, Rang M, Root L, Ferrari E, Yebenes Prous JG, Smith BP, Turkel C, Walcott JM, Molloy PT. Botulinum toxin type a neuromuscular blockade in the treatment of equinus foot deformity in cerebral palsy: a multicenter, open-label clinical trial. Pediatrics 2001;108(5):1062-71. Crossref

20. Tedroff K, Granath F, Forssberg H, Haglund-Akerlind Y. Longterm effects of botulinum toxin $A$ in children with cerebral palsy. Dev Med Child Neurol 2009;51(2):120-7. Crossref

21. Mohamed KA, Moore AP, Rosenbloom L. Adverse events following repeated injections with botulinum toxin $A$ in children with spasticity. Dev Med Child Neurol 2001;43(11):791-2. Crossref

22. Pirazzini M, Rossetto O, Eleopra R, Montecucco C. Botulinum neurotoxins: Biology, pharmacology, and toxicology. Pharmacol Rev 2017;69(2):200-35. Crossref

23. Mazzocchio R, Caleo M. More than at the neuromuscular synapse: actions of botulinum neurotoxin $A$ in the central nervous system. Neuroscientist 2015;21(1):44-61. Crossref

24. Heinen F, Desloovere K, Schroeder AS, Berweck S, Borggraefe I, van Campenhout A, Andersen GL, Aydin R, Becher JG, Bernert G, Caballero IM, Carr L, Valayer EC, Desiato MT, Fairhurst C, Filipetti P, Hassink RI, Hustedt U, Jozwiak M, Kocer SI, Kolanowski E, Krägeloh-Mann I, Kutlay S, Mäenpää $\mathrm{H}$, Mall V, McArthur P, Morel E, Papavassiliou A, PascualPascual I, Pedersen SA, Plasschaert FS, van der Ploeg I, RemyNeris O, Renders A, Di Rosa G, Steinlin M, Tedroff K, Valls JV, Viehweger E, Molenaers G. The updated European Consensus 2009 on the use of Botulinum toxin for children with cerebral palsy. Eur J Paediatr Neurol 2010;14(1):45-66. Crossref

25. Kanda T, Pidcock FS, Hayakawa K, Yamori Y, Shikata Y. Motor outcome differences between two groups of children with spastic diplegia who received different intensities of early onset physiotherapy followed for 5 years. Brain Devt 2004;26(2):118-26. Crossref

26. Fetters L, Kluzik J. The effects of neurodevelopmental treatment versus practice on the reaching of children with spastic cerebral palsy. Phys Ther 1996;76(4):346-58. Crossref

27. Corry IS, Cosgrove AP, Duffy CM, McNeill S, Taylor TC, Graham HK. Botulinum toxin A compared with stretching casts in the treatment of spastic equinus: a randomised prospective trial. J Pediatr Orthop 1998;18(3):304-11. Crossref

28. Flett PJ, Stern LM, Waddy H, Connell TM, Seeger JD, Gibson SK. Botulinum toxin A versus fixed cast stretching for dynamic calf tightness in cerebral palsy. J Paediatr Child Health 1999;35(1):71-7. Crossref 
29. Ackman JD, Russman BS, Thomas SS, Buckon CE, Sussman M D, Masso P, Sanders J, D'Astous J, Aiona MD. Comparing botulinum toxin $A$ with casting for treatment of dynamic equinus in children with cerebral palsy. Dev Med Child Neurol 2005;47(9):620-7. Crossref

30. Dursun N, Gokbel T, Akarsu M, Dursun E. Randomized controlled trial on effectiveness of intermittent serial casting on spastic equinus foot in children with cerebral palsy after botulinum toxin-A treatment. Am J Phys Med Rehab 2017;96(4):221-5. Crossref

31. Hayek S, Gershon A, Wientroub S, Yizhar Z. The effect of injections of botulinum toxin type $A$ combined with casting on the equinus gait of children with cerebral palsy. Bone Joint J 2010;92-B(8):1152-9. Crossref

32. Kay RM, Rethlefsen SA, Fern-Buneo A, Wren TAL, Skaggs DL. Botulinum toxin as an adjunct to serial casting treatment in children with cerebral palsy. J Bone Joint Surg Am 2004;86A(11):2377-84. Crossref

33. Desloovere K, Molenaers G, Jonkers I, De Cat J, De Borre L, Nijs J, Eyssen M, Pauwels P, Cock PD. A randomized study of combined botulinum toxin type $A$ and casting in the ambulant child with cerebral palsy using objective outcome measures. Eur J Neurol 2001;8(Suppl 5):75-87. Crossref
34. Love SC, Novak I, Kentish M, Desloovere K, Heinen F, Molenaers G, O'Flaherty S, Graham HK. Botulinum toxin assessment, intervention and after-care for lower limb spasticity in children with cerebral palsy: international consensus statement. Eur J Neurol 2010;17(Suppl 2):9-37. Crossref

35. Bottos M, Benedetti MG, Salucci P, Gasparroni V, Giannini $\mathrm{S}$. Botulinum toxin with and without casting in ambulant children with spastic diplegia: a clinical and functional assessment. Dev Med Child Neurol 2003;45(11):758-62. Crossref

36. Figueiredo EM, Ferreira GB, Moreira RCM, Kirkwood RN, Fetters L. Efficacy of ankle-foot orthoses on gait of children with cerebral palsy: Systematic review of literature. Pediatr Phys Ther 2008;20(3):207-23. Crossref

37. Coffey RJ, Cahill D, Steers W, Park TS, Ordia J, Meythaler J, Herman R, Shetter AG, Levy R, Gill B, Smith R, Wilberger J, Loeser JD, Chabal C, Feler C, Robertson JT, Penn RD, Clarke A, Burchiel KJ, Leibrock LG. Intrathecal baclofen for intractable spasticity of spinal origin: results of a long-term multicenter study. J Neurosurg 1993;78(2):226-32. Crossref

38. Wright FV, Sheil EM, Drake JM, Wedge JH, Naumann S. Evaluation of selective dorsal rhizotomy for the reduction of spasticity in cerebral palsy: a randomized controlled trial. Dev Med Child Neurol 1998;40(4):239-47. Crossref 